\title{
Review
}

\section{Science on air: a journey through early science programmes in US radio}

\author{
Matteo Merzagora
}

Marcel Chotkowski LaFollette, Science on the air, The University of Chicago Press (2008).

\begin{abstract}
Science on the air" is an enjoyable and extremely well researched account of the origins of science programming in north American radio. From 1923 to the mid-50s, LaFollette takes us in a journey through the life and programs of many scientists, journalists and storytellers who chosed radio as a medium for science communication. A journey who allow the reader to visit many success, but also many incomprehension and missed opportunities, mainly by scientific institutions, who often failed to understand the potential of radio as a tool for science communication. It is a fully enjoyable journey, that leave the reader with an appetite to know how the US situation relates to other wonderful experiences around the world in the same years, and how those pioneer experiences influenced today's landscape.
\end{abstract}

When browsing through the rich bibliography of Marcel LaFollette's book Science on the air, one immediately observe three main features. Only a handful of books or papers quoted are published after 2000; almost no reference point to science and technology studies or science communication studies; almost no reference concerns studies published outside the Anglo-Saxon world. These observations outline the three main drawbacks of the book.

But it is worth coming back to them only after having reported about the pleasure of reading an informative, well documented, well written, intelligent account of a little known facet of science communication history. In another recent book about science in radio broadcasting ${ }^{1}$ (focused on Europe and on present time) we denounced the void that surrounds the analysis of the role of the radio in science communication, if compared with the analysis of other media such as television or science centres, quoting LaFollette's earlier works as a notable exception. This new book is therefore highly welcomed.

The corpus of LaFollette research concentrates on the early history of science in radio broadcasting in the United States (with a chapter devoted to television: we will not discuss it here, as LaFollette is reportedly working on a full book about science and early television and we look forward to review it): the book "chronicles the efforts of [those] popularizers, from 1923 to the mid-1950s, as they negotiated for time on the air". By applying all the best practices of a radio report, LaFollette transform a meticulous work in the archives of the Science Service agency and other science popularisation experiences on air into a captivating account of the efforts, the achievements and the ideologies of a number of fascinating men (and too few women, as she does not fail to underline...). If their efforts and their achievements is what makes the reading of the book truly enjoyable, it is their ideology, or more simply their views about the role of the radio in science communication, that is probably of specific interest for the Jcom reader.

Thanks to this account, we can appreciate how many different views of science communication can exists and have existed or cohexisted over the years. According to Austin Hobart Clark, for example, a curator of the Smithsonian Institution to whom we owe one of the first science chronicles in American radio, in 1923, science talks on the radio "must be wholly accurate, dignified, and without reference to controversial points", which would "discredit" science. A principle used to justify avoiding talking about evolution, for example. This view did not prevent Clark to establish a long lasting personal and professional friendship with Thornton Burgess, author of children books on nature, initiator of the Radio Nature League, who used the radio to mobilize young Americans in preservation efforts. Burgess (as 
several of the other characters of the cast) comes out of LaFollete account as a wonderful story teller whose stories we would love to listen in a multimedia version of the book... He and Clark managed to promote what we would now call "bottom-up" science, convinced that the radio medium "had significant potential for gathering as well as giving out scientific information", for example by asking (and obtaining) the listeners to monitor an unusual flight of three species of white herons in 1925.

Another friendship, the one between scientist William Emerson Ritter and newspaper publisher Edward Willis Scripps, is at the origin of the Science Service and its evolution toward an independent and influential news service. The two men understood the need of scientific institutions to conquer public support, and at the same time that "there are aspects of science that appeal strongly to popular interest. There is much that is curiosity-satisfying, much that is practically useful, much that is dramatic". With an offer and a demand waiting to be connected, success was granted, but only if the right choices were made. For example, already in the 1920 s it was possible to trace a discussion - which continued up to our time - on the importance to make use of professional science communicators ("highly intelligent and sympathetic... though not necessarily trained in science") and/or of scientists experts in the contents, but that would need to be trained to gain "considerable sympathetic attention to the problem of the deeper social relation of science", since "the obligation of science... to discover its own meaning for human life is not one whit less pressing upon it than is its obligation to discover the truths of nature" (quotes are from William E. Ritter correspondence in 1920). Training good journalists and engaging scientists were elements incorporated in a vision of "shared responsibility" on which Science Service based its success, and that we still find central in many debates on science communication today. The same is true for the assessment of the meaning of "breaking news" or "hot news" in science, a topic that challenged other major protagonists of early science radio history, such as chemist Edwin Emery Slosson - the first to head Science Service - or the managing editor Watson Davis (to whom LaFollete attribute the merit of bringing journalistic skills and "noses" to science reporting: another voice that we wish to ear one day...).

LaFollete book proceed in introducing and following the deeds of many fascinating historical characters, while at the same time providing an overview of many issues relevant for science in radio broadcasting in the period analysed, but we could easily say also today. Namely the educational role of radio, its close relationship with the public of the listeners, the opportunities and risks to present science through fiction, the way radio can and does allow scientists to express their personalities through the interaction with the presenters, the way in which, "having previously been dramatized and humanized", in wartime period radio "became politicized".

Having said this, it is worth spending few lines on what can be considered the weaker points of the book, as they emerge from the analysis of the bibliography.

First, reference to science and technology studies and science communication studies are mostly absent, and only a handful of books and papers quoted were published in XXI century. This cannot be imputed to a lack of mastering of the topic: LaFollette is the author of several seminal papers and books on science popularization and she is an authority on the subject since many years, also as editor of the "Science Communication" magazine. Do we have to interpret this absence as a message that contemporary studies on public understanding of science and science in society issues are on a false route and fail to provide useful new knowledge? Or it is just the choice of an historian who wish to protect her analysis from the distorting lenses of contemporary preoccupations? Whatever the cause, the effect is a feeling of unease: readers, whether academics of practitioners of radio science programmes, would probably have benefited from clear statements clarifying the approach adopted and, most importantly, the overall goals of this work. Indeed, potentially interesting assertions such as "what seems astonishing in retrospect is how little the leaders of the scientific community seemed to respect broadcasting's power and potentials" and a reported "marginalization of science programming" which appear as a strong thesis of the book, leave the reader with more appetite than they satisfy.

Secondly, almost no reference is included to studies conducted outside the Anglo Saxon world. Indeed, this is is a general tendency of studies originating in the US and UK, which has a very negative impact on the general advancement of knowledge. We could quote, for example (and not to refer to the obvious BBC, Radio France or Deutsche Welle experiences, all happening in the same years), the very interesting account of the origins of radio broadcasting in Brazil as a science communication tool in $1923^{2}$, the very same year in which the account of LaFollette begins. Although outside of the focus of the book, readers of what is at present the most complete account of the history of science in radio broadcasting would 
have benefited to have at least a superficial overview of what was happening in the rest of the world at the same time.

Set aside these negative elements, minors if compared to the interesting elements sketched above, we wish to conclude with a quote by pioneer Austin Hobart Clark reported in Science on the air, that very well summarizes the feeling of anyone who experienced working at (as a practitioner) or on (as a researcher) a radio programme, and also the feeling that the readers of this book will probably take home: "all of those who have talked over the radio... have acquired a wholly new concept of popular science, and the training they have received will not soon be forgotten".

\section{Notes and references}

1 M. Mazzonetto, M. Merzagora and E. Tola, Science in radio broadcasting, the role of the radio in science communication, Polimetrica (2005).

2 L. Massarani, I. de C. Moreira and F. Brito (Eds), Ciência e Público. Caminhos da Divulgação Científica no Brasil, Casa da Ciência e Editora da UFRJ (2002).

How TO CITE: M. Merzagora, Science on air: a journey through early science programmes in US radio, Jcom 08(01) (2009) R01 